\title{
Um olhar sobre as competências requeridas aos profissionais de gestão de pessoas que atuam em cooperativas agroindustriais do Paraná
}

\author{
An overview about required skills for people management professionals acting on \\ agroindustrial cooperatives of Paraná
}

\begin{abstract}
Resumo
Observando o crescente interesse no meio acadêmico e empresarial em relação ao conceito de competência e tendo em vista que as cooperativas apresentam posição de destaque na sociedade, o presente trabalho buscou conhecer as competências requeridas aos profissionais que atuam em departamentos de gestão de pessoas em cooperativas agroindustriais do estado do Paraná. A partir de um questionário aplicado a esse público, obtiveram-se como resultado as cinco seguintes competências: capacidade de trabalhar em equipes; capacidade de lidar com situações novas e inusitadas; capacidade de comunicação; capacidade de relacionamento interpessoal; e capacidade de dar foco ao cliente, estabelecendo relação de confiança e assegurando longo prazo a ela. No entanto, no que se refere ao entendimento dos participantes sobre o conceito de competência, observou-se uma diversidade de enfoques nas respostas, o que pode estar relacionado à inexistência de um consenso sobre o assunto por parte da população estudada. Assim, ressalta-se a relevância de novos estudos a fim de aprofundar as discussões acerca desta temática, podendo oferecer conhecimentos úteis à sociedade, ao público acadêmico e especialmente aos profissionais da área e cooperativas.
\end{abstract}

Palavras-chave: competência, Gestão de pessoas, Cooperativismo, Agroindústrias.

\begin{abstract}
Observing the growing interest in the academic and business environment in relation to the concept of competence and considering that the cooperatives present a prominent position in society, the present work sought to know the skills required for professionals who work in departments of people management in agroindustrial cooperatives in the state of Paraná. From a questionnaire applied to this public, the following five competences were obtained: capacity to work in teams; ability to deal with new and unusual situations; Communication capacity; interpersonal relationship capacity; and ability to focus on the client, establishing trust and ensuring long-term relationship. However, with regard to the participants' understanding of the concept of competence, a diversity of approaches was observed in the responses, which may be related to the lack of consensus on the subject by the population studied. Thus, the relevance of new studies is emphasized in order to deepen the discussions about this subject, being able to offer useful knowledge to the society, to the academic public and specially to the professionals of the area and cooperatives.
\end{abstract}

Keywords: competence, people management, cooperatives, agroindustries.

Isabela Makiyama ${ }^{\text {I }}$, Laís Raycik ${ }^{\text {II }}$, Letícia Gabriela Cassol Biavatt ${ }^{\text {III }}$.

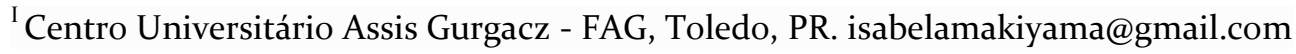

${ }^{\text {II }}$ Centro Universitário Assis Gurgacz - FAG, Toledo, PR. laisraycik@hotmail.com

${ }^{\text {III }}$ Centro Universitário Assis Gurgacz - FAG, Toledo, PR. leticiagbiavatti@gmail.com 


\section{Introdução}

O presente trabalho buscou conhecer as competências requeridas aos profissionais que atuam em departamentos de gestão de pessoas em cooperativas agroindustriais do estado do Paraná.

A escolha por esse tema deu-se pelo crescente interesse observado tanto no meio acadêmico quanto no meio empresarial em relação ao conceito de competência. Considerando-se que pouco referencial teórico é encontrado no que diz respeito às competências no âmbito das cooperativas, visto que estas também estão aderindo ao mesmo e ocupam posição de destaque em relação à produção e exportação de produtos, além do grande número de associados e empregados vinculados, conforme o relatório da Coordenação de Desempenho (Gecoop), em 2018 foram contabilizados 170.793 cooperados e 82.421 funcionários nas 61 cooperativas do estado do Paraná (SISTEMA OCEPAR).

Entende-se que é necessário explorar o sistema cooperativista, já que os desafios e as mudanças são cada vez mais frequentes nesse ambiente competitivo, algo que já era apontado por Waack e Machado Filho, em 1999 e foi reafirmado por França (2013), o qual destaca que o desafio deste departamento é integrar pessoas e competitividade, o que gera ações complexas que objetivam sintonizar colaboradores e necessidades da empresa. Considerando que o sistema cooperativista detém valores e princípios próprios, mas, por outro lado, está inserido em um mercado cada vez mais exigente, é fundamental compreender quais competências podem auxiliar os profissionais que atuam nos departamentos de gestão de pessoas a suprir as complexas demandas organizacionais, visto que, com o passar do tempo, reconhece-se o crescente papel desse setor como um diferencial estratégico e competitivo para a organização.

Tendo em vista que a equipe de Gestão de Pessoas é o "coach dos coaches dentro da organização" (RABAGLIO, 2015, p. 13), a qual é responsável pelas atividades de captação de talentos e atores ativos no planejamento de ações de desenvolvimento de competências dos colaboradores, é de suma relevância o entendimento sobre as competências requeridas aos profissionais que atuam nessa área, visto também que o próprio setor passou por evoluções e modificações ao longo do tempo. Neste sentido, uma mudança significativa sobre a gestão de pessoas nas organizações relaciona-se a uma visão mais estratégica nos dias de hoje, considerando o elemento humano, ou seja, as pessoas, como participativas dos resultados empresariais. Durante muito tempo os indivíduos foram vistos somente como recursos (TACHIZAWA, FERREIRA E FORTUNA, 2006).

Para isto, definiram-se objetivos direcionados à verificação do entendimento dos participantes da pesquisa acerca do conceito de competência; ao levantamento da percepção dos profissionais que atuam no departamento de gestão de pessoas em cooperativas, sobre as competências necessárias para o exercício profissional; e à relação das competências apontadas pelos participantes com as competências organizacionais disponibilizadas pelas cooperativas.

A revisão bibliográfica direcionou-se para o entendimento dos conceitos de competências, gestão de pessoas e cooperativismo, que serão apresentados na sequência, com o objetivo de respaldar as discussões posteriores.

\section{Gestão de Pessoas}

A gestão de pessoas avançou a partir de atividades operacionais, para uma visão estratégica dentro das organizações. Tendo então a difícil missão de integrar pessoas e competitividade, gerando ações complexas que objetivam sintonizar as pessoas e as necessidades da empresa. Sendo assim, é definida como um "conjunto de forças humanas voltadas para as atividades produtivas, gerenciais e estratégicas dentro de um ambiente organizacional” (FRANÇA, 2013, p. 3-5). 
Dutra, G. A. (2017), Dutra, J. S. (2017) e Dutra, T. A. (2017), ao se referirem sobre as mudanças na forma de gerir pessoas, atribuem a estas o fato de que as organizações têm sofrido grande pressão externa, o que as leva a uma revisão de suas concepções sobre o tema. Para os autores, as principais mudanças englobam a demanda por pessoas que se adaptem às formas flexíveis de estruturação do trabalho, sendo capazes de participar de decisões ágeis e focadas no negócio, o que torna necessário que as mesmas estejam sempre atualizadas em relação às tendências nacionais e internacionais. Os autores ainda apontam o alto grau de competitividade do mercado atual, que exige pessoas bem articuladas, que formem um time em constante aprimoramento.

Com o processo de globalização e consequentemente a maior complexidade e velocidade das mudanças, as organizações passaram a necessitar e priorizar algumas características nos colaboradores, entre elas, pessoas com mais iniciativa e comprometidas com os objetivos e estratégias organizacionais. A partir desta perspectiva, Dutra (2017, p. 2.), salienta que "o atual e grande desafio da gestão de pessoas é gerar e sustentar o comprometimento delas, o que só é possível se as pessoas perceberem que sua relação com as organizações lhes agrega valor".

Visto que a gestão de pessoas nas organizações passou por uma evolução ao longo dos anos e que encontra até hoje grandes desafios, cabe aos envolvidos nesse processo encontrar estratégias para a obtenção dos resultados desejados, que sejam também um diferencial competitivo para a organização. Essa visão estratégica torna-se eficaz "[...] a partir do gerenciamento da cultura da organização, do desenvolvimento de novas competências, da formação de equipes e do desenvolvimento das pessoas no processo de transformação" (ÁVILA e STECCA, 2015, p. 22).

A partir desse contexto de transformações, as organizações, atualmente, passariam a agir e pensar dentro de uma perspectiva voltada ao alcance de resultados, os quais podem influenciar o tempo de permanência da empresa no mercado de trabalho. Segundo Barbieri (2016), diante desse cenário desafiador, a gestão de pessoas poderá oferecer uma visão estratégica da organização e do negócio, aproximando os colaboradores, que passam a ser percebidos como sujeitos ativos nas empresas.

Assim, a gestão de pessoas (GP), também conhecida como RH, oferece ações e instrumentos que possibilitam o desenvolvimento da empresa e de suas equipes. Conforme Dutra, G. A. (2017), Dutra, J. S. (2017) e Dutra, T. A. (2017), considerando que as empresas dependem cada vez mais de pessoas comprometidas com suas estratégias e negócio, torna-se necessário que as mesmas consigam encontrar em sua relação com a organização, vantagens concretas para si próprias, o que não se dá com discursos bem feitos, salários, benefícios ou facilidades. Neste sentido, Barbieri (2016), pontua algumas atividades que poderão ser realizadas pelos profissionais do setor de recursos humanos, entre elas: procurar adequar a visão de futuro, sistema de gestão, cultura e a realidade do negócio, colocando a pessoa certa, no lugar certo, com as competências necessárias para o bom desempenho no cargo, no prazo que foi solicitado pelos seus clientes internos. Além disso, priorizar a avaliação de potencial e desempenho e a educação continuada e o desenvolvimento das competências dos colaboradores. Do mesmo modo, priorizar ações de qualidade, produtividade, de inovação e criatividade, assim como facilitar o empowerment dos mesmos, dando-lhes acesso à informação e ao conhecimento do negócio.

Desta forma, baseando-se nas funções apresentadas por Barbieri (2016), entende-se que a gestão de pessoas passa a ser compreendida cada vez mais por sua visão estratégica do negócio. Para tanto, é necessário concretizar essas estratégias, criando e implementando recursos para o aumento da competitividade, do lucro e oferecendo melhores produtos e serviços, assegurando a satisfação dos clientes e consequentemente produzindo efeitos desejáveis para a organização. 
Contudo, o uso inadequado de conceitos e ferramentas pela gestão de pessoas, criará o que Dutra (2017), define como efeitos perversos. Segundo o autor, os efeitos indesejáveis mais encontrados atualmente são: desarticulação conceitual (ausência de articulação entre conceitos e prática), exploração do trabalhador (não valorização, exposição do trabalhador e risco profissional), descolamento estratégico (pouco compromisso da gestão de pessoas com os objetivos estratégicos) e desarticulação com as pessoas (ausência de articulação com as expectativas e necessidades das pessoas).

Sendo assim, para evitar o surgimento desses efeitos perversos, é necessário que dirigentes e organizações mantenham-se alertas, principalmente à conciliação de expectativas e necessidades da organização e dos indivíduos. Segundo Dutra, G. A. (2017), Dutra, J. S. (2017) e Dutra, T. A. (2017), tendo em vista que são os gestores e as lideranças que fazem a intermediação entre pessoas e organização, fica claro que os mesmos têm importante papel nessa tarefa. Assim, deve haver uma preocupação contínua na seleção, preparação e desenvolvimento dos ocupantes dos cargos.

Com base no que foi exposto, percebe-se que gerir pessoas não é trabalho fácil, e deve-se desenvolver novas formas para isso, já que é uma área ainda em consolidação. Conforme Dutra (2017), no cenário atual, as organizações necessitam atender demandas mais exigentes, e consequentemente estão adotando sistemas de gestão de pessoas que utilizam alguns conceitos, como o de competências. O autor supracitado destaca que no Brasil, as organizações que estão adotando o conceito, vêm conquistando ganhos.

No entanto, a utilização desse termo, não será necessariamente apropriada, já que dependerá de como a organização o aplicará. Dutra (2017, p. 305), evidencia que "é bem provável, que a maior parte os empregue como forma de extrair mais resultados das pessoas, sem nenhuma preocupação em patrocinar o desenvolvimento delas". Por outro lado, a gestão de pessoas poderá utilizar outros conceitos complementares que agreguem e possam auxiliar no levantamento das competências requeridas pela empresa e pela sociedade, e aproveitá-las para desenvolver as pessoas e assegurar vantagens competitivas, além de oferecer melhor foco aos propósitos da organização.

Neste sentido, Barbieri (2016, p. 42), destaca algumas competências que os dirigentes passaram a buscar nos colaboradores, diante das incertezas na economia local e global. O autor menciona os seguintes exemplos: "o pensamento estratégico, a liderança e o trabalho em equipe, a habilidade de se comunicar e negociar, a capacidade de realizar mudanças, a persistência e a resistência a frustrações [...]”. Nos gestores, buscam principalmente aqueles que tenham pensamento estratégico, ou seja, que consigam observar pontos fracos e fortes, riscos e possibilidades da organização e do negócio, sendo necessário a capacidade de integrar estas características com a prática do dia a dia.

Evidencia-se que muitas empresas estão conseguindo resultados positivos a partir das novas propostas de gestão de pessoas, contudo, ainda não se dispõe de um modelo de gestão confiável, capaz de substituir completamente o modelo tradicional (DUTRA, 2017). Na década de 1970, David McClelland propôs pela primeira vez, de forma estruturada, o conceito de competência. Ele pretendia com isso, desenvolver uma maneira mais efetiva para selecionar pessoas para as organizações. Posteriormente, o conceito de competência utilizado pelos franceses ajudou no entendimento sobre como as pessoas podem contribuir para o desenvolvimento da organização. Entendia-se que uma pessoa é competente quando utiliza de sua capacidade para atender as demandas de seu contexto. Desta forma, para conseguir agregar valor, é necessário que esse indivíduo compreenda qual demanda está se apresentando em seu meio. No entanto, no contexto atual, atingir metas e fazer as atividades corretamente não representa uma contribuição tão significativa, as exigências que caem sobre as pessoas são ainda maiores que isso (DUTRA, G. A., 2017; DUTRA, J. S., 2017 e DUTRA, T. A., 2017). 
A palavra "competência" é bastante utilizada pelo senso comum para caracterizar uma pessoa que é qualificada para fazer algo, tendo seu antônimo um sentido pejorativo. No entanto, nos últimos tempos, o termo passou a fazer parte do âmbito acadêmico e empresarial, sendo abordado em diferentes níveis: da pessoa (individual), da organização e dos países (FLEURY e FLEURY, 2001).

Aqui, é importante que se entenda principalmente os dois primeiros níveis supracitados, desta forma, Fleury e Fleury (2013), definem competência individual como sendo os recursos detidos por uma pessoa, que pode ser avaliada em relação às atividades desempenhadas no cargo que ocupa dentro da empresa. Já o conceito de competência organizacional é definido por Fernandes (2013), como a combinação de recursos que fornecem vantagem competitiva para a organização.

Assim, existe entre as pessoas e a organização uma troca contínua de competências. Por um lado, a organização prepara as pessoas para o enfrentamento de novos desafios profissionais e pessoais, por outro, as pessoas transferem à organização tudo aquilo que aprenderam. Assim, podese dizer que são as pessoas que concretizam e aprimoram as competências organizacionais, agregando valor às mesmas, o que permite manter as suas vantagens competitivas no decorrer do tempo. Desta forma, competências organizacionais e individuais se influenciam mutuamente (DUTRA, G. A., 2017; DUTRA, J. S., 2017 e DUTRA, T. A., 2017).

Para Rabaglio (2015, p. 9-10), o termo competência possui três "ingredientes", que são representados pela sigla "CHA": Conhecimentos, Habilidades e Atitudes. Sendo que os dois primeiros se referem às competências técnicas, e o último, às competências comportamentais. Há algumas décadas o mercado de trabalho não valorizava e não reagia de forma positiva às questões comportamentais. Assim, os processos de gestão de pessoas como a admissão, promoção, movimentação e desligamento de colaboradores eram realizados levando-se em conta apenas as competências técnicas, o que ocasionou em prejuízos para as empresas. Hoje, sabe-se que um candidato precisa ter compatibilidade com o "CHA" completo de que o cargo necessita, pois assim, obter-se-á eficácia nos resultados. Desta forma, competência, dentro das organizações, é um termo que se refere ao conjunto de conhecimentos, habilidades e atitudes que se necessita para cada cargo.

Ao falar em competência, Santiago (2008, p. 21-22), enfatiza a entrega. Para este autor não basta apenas estar preparado para executar algo, é necessário executar efetivamente, pôr em prática. Assim, "competência é o conjunto de conhecimentos, habilidades e atitudes correlacionadas que em ação agregam valor ao indivíduo e à organização, ao que denominamos de entrega". O autor entende o conceito como uma manifestação conjunta dos três aspectos do "CHA" mencionados acima, no entanto, e por isso, não utiliza a distinção entre competência técnica e competência comportamental.

Assim como Santiago, autor supracitado, Dutra (2017), também utiliza o conceito de entrega para explicar a competência individual. Ele indica que a forma do indivíduo atuar, ou, a forma de se entregar ao trabalho, deve ser avaliada além de sua formação e experiência. A partir dessa entrega a organização poderá analisar seus colaboradores, direcionar o desenvolvimento dos mesmos e determinar recompensas, além de ser fator impactante na hora da admissão, demissão, aumento salarial, promoção, entre outros.

Le Boterf (2006), mencionando as três dimensões da competência ou profissionalismo, pontua que há a dimensão dos recursos disponíveis, que se referem aos conhecimentos, saber-fazer, capacidades cognitivas, competências comportamentais, as quais o indivíduo pode mobilizar para agir. A dimensão da ação e dos resultados que o mesmo produz, ou seja, estão relacionadas com as práticas profissionais e desempenho. E, há a dimensão da reflexividade, que se distancia das dimensões anteriores.

Percebe-se então, que alguns autores abordam sobre a temática competências, sobretudo no nível individual, definindo o termo por meio das variáveis seguintes: conhecimentos, habilidades e 
atitudes. Neste sentido, Fernandes (2013, p. 48), define as competências individuais como "um conjunto de conhecimentos, habilidades, atitudes e valores que um indivíduo mobiliza e aplica, de forma reiterada, dentro de um contexto profissional, agregando valor à organização e a si mesmo". E complementa que, para ser considerado competente, é necessário que o sujeito saiba como empregar essas variáveis.

Nesta perspectiva, Lopes (2014, p. 6), pontua que "a competência, portanto, não se coloca no âmbito dos recursos (conhecimentos, habilidades), mas na mobilização desses recursos e, portanto, não pode ser separada das condições de aplicação". No mesmo sentido, Barbieri (2016), destaca que a competência, além dos conhecimentos detidos pelo indivíduo, também é vista como a capacidade de concretizá-los na realização de uma atividade. Sendo assim, fica clara a evolução desse conceito, que antes se limitava às capacidades necessárias para determinada função, e hoje expande-se para as capacidades necessárias, aplicação e agregação de valor.

Assim, a partir das definições expostas, Camargo (2013), considera que esse conjunto seja o caminho para o bom desempenho do profissional e para o desenvolvimento da empresa. No entanto, é importante que essas características estejam associadas ao cargo que o sujeito ocupa, à organização e aos resultados almejados. Conforme Dutra (2017), existem competências organizacionais específicas de cada empresa, e competências individuais específicas para atender as demandas da organização.

Ressalta-se aqui, de acordo com Lopes (2014), que as competências individuais não se referem apenas às competências de um único indivíduo, mas dos membros que compõem a organização. Essas competências variam de pessoa para pessoa e podem ser combinadas para que a empresa consiga produzir e distribuir seus produtos e serviços de maneira qualificada ao mercado, que hoje é caracterizado por sua imprevisibilidade econômica.

Diante do exposto, é fundamental que além das competências individuais, as empresas também criem seu diferencial competitivo, o que podemos associar às competências organizacionais, assim, alinhando esses dois fatores, a consequência poderá ser o sucesso da organização. Lopes (2014, p. 46), destaca que as competências organizacionais "são competências difíceis de imitar". Por isso, devem ser diferentes das competências dos concorrentes, contribuir para o desenvolvimento da empresa e ofertar serviços diferenciados ao cliente.

Nessa perspectiva, conforme Fleury e Fleury (2013), dentre as competências organizacionais existem aquelas que podem ser denominadas essenciais (as core competences). Geralmente há uma ou algumas que podem receber essa denominação. A competência essencial de uma empresa é aquela que é imprescindível para realizar a estratégia competitiva da organização, e será definida com base em sua principal função. Para desenvolvê-las, é necessário um processo sistematizado de aprendizagem e inovação.

Portanto, entende-se que as competências organizacionais implicam nas decisões estratégicas adotadas pela organização. Ao realizar o mapeamento destas competências, será possível identificar o que ainda falta à organização para que a mesma seja capaz de efetivar sua estratégia. Para isso, Fernandes (2013, p. 34), retrata que é necessário que as competências organizacionais atendam alguns propósitos, como: "identificar capacidades ou recursos superados (que também são fraquezas), capacidades ou recursos estratégicos existentes e capacidades ou recursos estratégicos potenciais". Isso significa que, competências passadas podem não condizer mais com o negócio, sendo necessário rever o que é um fator competitivo no presente e no futuro reconsiderar que competências serão importantes para o momento.

De acordo com Camargo (2013, p. 39), “competência é, portanto, o resultado entre o aprimoramento do indivíduo e colaboração deste para o desenvolvimento da organização em que atua". Com isso, o conceito relaciona-se à forma como as habilidades individuais e organizacionais são mais bem aproveitadas dentro da organização. 
Diante do exposto, Dutra (2017, p. 18), menciona que as competências individuais devem ser atreladas às competências essenciais da organização, isso significa que espera-se dos colaboradores a entrega do que é necessário e importante para o desenvolvimento da empresa. Ao entregar o que é necessário, o indivíduo estará agregando "valor ao patrimônio de conhecimentos da organização".

O mesmo autor supracitado destaca que o entendimento de agregação de valor como algo que a pessoa oferece para a organização de forma efetiva, isto é, que permanece mesmo quando a pessoa sai da organização. Deste modo, a agregação de valor não é só atingir metas de faturamento ou de produção, mas sim, aprimorar processos ou introduzir tecnologias.

Conforme Sant'Anna et al. (2016, p. 310), a modernidade vem para evidenciar a necessidade das organizações estarem prontas para "enfrentar a competição nos padrões da nova configuração do mundo dos negócios”, adotando para isso, estratégias e práticas de gestão que sejam favoráveis a construção de contextos que estimulem um comportamento competente.

Desta forma, Dutra (2017), destaca que as pessoas devem apropriar-se do conceito de competência, para que então, o mesmo possa ser aperfeiçoado. Assim, devem compreender genuinamente o termo e utilizá-lo para o desenvolvimento de organizações e pessoas.

\section{Cooperativismo e Gestão de Pessoas}

O cooperativismo surgiu na Inglaterra no período da Revolução Industrial, com o agrupamento de tecelões. Esses trabalhadores passaram a estabelecer um certo tipo de relação, visto que possuíam objetivos em comum, ou seja, comprar coletivamente produtos necessários à sobrevivência, pois passavam por dificuldades (como o desemprego ou salários baixos). Assim, criaram a Associação dos Probos Pioneiros de Rochdale, e, mais tarde, fundaram a cooperativa Rochdale "cuja função inicial era conseguir capital para aumentar o poder de compra coletiva" (CARDOSO, CARNEIRO e RODRIGUES, 2014, p. 7).

A ideia dos tecelões, posteriormente, expandiu-se para outros países e hoje as cooperativas são reconhecidas como instituições importantes para o desenvolvimento do planeta. Conforme Cardoso, Carneiro e Rodrigues (2014), a cooperação é um tema cada vez mais presente nas discussões, já que empresas com esta característica vêm ocupando espaço significativo na sociedade, pois influenciam e aceleram o desenvolvimento econômico e social.

Neste sentido, Reisdorfer (2014, p. 18), definiu as organizações cooperativas como "entidades complexas, com muitos interesses envolvidos". O referido autor acrescenta que as organizações cooperativas nascem, como resultados de interações sociais, da articulação e da associação de indivíduos que se identificam por interesses ou necessidades comuns. Essas organizações buscam o seu fortalecimento pela coordenação e instrumentalização, com vistas a alcançar objetivos e resultados de ordem econômica, social e ambiental, que sozinhos seriam mais difíceis de atingir. Constituir uma organização cooperativa constitui a princípio, um acordo racional de um grupo de pessoas sobre o mercado, de modo que os seus interesses e necessidades frente à produção e distribuição de bens e riquezas seja mais equitativo. Nesse contexto, se desenvolve política e operacionalmente, nos espaços da organização cooperativa, mediada pela comunicação, processos coletivos, conforme seus objetivos comuns.

De acordo com a OCB (Organização de Cooperativas Brasileiras), uma cooperativa é constituída por um grupo de pessoas que compartilham de um mesmo objetivo e "todos são donos do próprio negócio". Ao atingir sua finalidade, a cooperativa contribui para o país, para o mundo e traz resultados também aos associados. Ressalta-se que os ramos do cooperativismo são diversos, entre eles: agropecuário, de consumo, de crédito, habitacional, de produção, mineral, de trabalho, de saúde, de turismo e lazer, entre outros. 
Conforme Reisdorfer (2014), no congresso da Aliança Cooperativa Internacional, no ano de 1995, foi finalizada a mais recente reformulação dos princípios cooperativistas. Isso, porque o desenvolvimento quantitativo e empresarial das cooperativas fez com que os valores básicos do cooperativismo fossem substituídos pela eficiência econômica e administrativa. Até mesmo pela necessidade de encontrar respostas mais eficazes ao crescente desafio de um mercado altamente competitivo e monopolista, devido a globalização, e ainda assim, procurar manter o sentido de benefício econômico e social ao quadro associativo.

Foram definidos então os seguintes princípios cooperativistas: Adesão voluntária e livre; gestão democrática pelos membros; participação econômica dos membros; autonomia e independência; educação, formação e informação; intercooperação e interesse pela comunidade (ALIANÇA COOPERATIVA INTERNACIONAL - ACI, 1995).

Tendo em vista os princípios cooperativistas, Waack e Machado Filho (1999, p. 149), observam que este é um modelo de difícil gestão, já que tem de lidar com demandas muito distintas entre si, no qual cada cooperado tem o seu voto. "A governança se torna muito complexa [...], carece de profissionais na gestão, distancia-se do mercado, focalizando-se na produção. Pela heterogeneidade de interesses, acaba por ter problemas de escala e falta de foco em negócios". Desta forma, os autores destacam o crescente número de desafios enfrentados pelas cooperativas em geral, pois, ao mesmo tempo em que necessitam sobreviver em um mercado totalmente competitivo, não podem desgarrar-se de seus princípios doutrinários.

Com as alterações políticas e econômicas que ocorreram no Brasil nas décadas de 8o e 90, as cooperativas foram pressionadas a se ajustarem, no sentido de se ampliarem, para manterem sua participação no mercado. Diante desse contexto, muitas cooperativas ficaram endividadas, tornaram-se insolventes ou perderam participação no mercado. No entanto, outras progrediram administrativamente e se sobressaíram competitivamente, preservando a sua identidade como cooperativa (FERREIRA e BRAGA, 2004).

Desta forma, tendo em vista essa possível dicotomia, Cançado, Souza e Pereira (2014), enfatizam a importância de que as cooperativas melhorem suas formas de comunicação, de forma que fortaleça a cooperação entre os seus cooperados. Ocorrendo assim, a tomada de maiores responsabilidades em relação à cooperativa. Os autores ainda ressaltam que em empresas maiores, o tamanho da organização pode ser um fator que dificulte essa participação, assim, propõem também a ampliação dos meios de participação, a exemplo das pré-assembleias.

Conforme Carvalho e Silva (2017), a gestão de pessoas nas cooperativas tem em sua função o desenvolvimento dessa organização perante os associados, além de proporcionar características íntegras, com o propósito de que novos membros possam aderir ao sistema. Para isso, a gestão de pessoas deverá apresentar ferramentas estratégicas que correspondam aos interesses dos envolvidos e ao cenário competitivo enfrentado pela organização.

Entende-se então, que a Gestão de Pessoas nestas organizações é um grande desafio, visto que possuem diversas peculiaridades, como a "gestão democrática, participação econômica dos membros, preocupação com a comunidade, intercooperação, retorno pró-rata das sobras, educação cooperativista e adesão livre e voluntária”. Conforme os autores, esse conjunto de princípios cria uma cultura organizacional diferenciada em relação às demais organizações com fins econômicos. "Como a eficiência dos colaboradores está diretamente relacionada a adequação destes à cultura organizacional, podemos presumir que os funcionários de cooperativas precisam ser diferenciados" LADEIRA, VIEIRA e CAMPOS, 2011, p. 2).

Bitencourt et al. (2010), esclarece que a gestão de pessoas, gestão social e recursos humanos devem conhecer e compreender sobre o cooperativismo. Assim, poderão elaborar estratégias que 
estarão de acordo com os princípios e valores de uma organização cooperativa, como democracia, equidade, entre outros.

Falando especificamente sobre o cooperativismo paranaense, percebe-se que o mesmo se constituiu com base nos ciclos da produção de erva-mate, madeira e café, ao menos no que tange o período que vai até o final dos anos de 1960. A crescente oferta de café, no entanto, levou à diminuição dos preços, passando as cooperativas a ter foco na produção de soja, trigo, milho e algodão, o que levou a diversificação de suas atividades. Nesta época, a atividade das cooperativas era permeada por dificuldades relativas a serviços e infraestrutura (KOSLOVSKI, 2018).

As políticas voltadas à industrialização da agricultura foram desenvolvidas ao final dos anos 1960. Elas objetivaram suprir a demanda interna, além do crescente aumento das exportações. Assim, esses anos finais foram considerados como o marco da constituição do complexo agroindustrial brasileiro (ALENCA et al., 2001).

No entendimento do autor acima citado, a característica central da constituição dos complexos agroindústrias é a integração da agropecuária com outros ramos industriais, transformando-a em um elo de uma cadeia onde se encontram de um lado, as indústrias que fornecem à agricultura insumos, máquinas e equipamentos (setor a montante) e, do outro, as indústrias de classificação, beneficiamento e/ou industrialização da matéria-prima agrícola, bem como a sua distribuição (setor a jusante).

Atualmente, as cooperativas agropecuárias são representativas de cerca de $55 \%$ da economia agrícola paranaense. Em muitos municípios, é a mais importante empresa, tanto no que diz respeito à economia, geração de empregos e de receitas. Assim, além de trazer benefícios sociais, as cooperativas são importantes no sentido de que propiciam condições para a produção agropecuária, contribuem para o aumento da renda dos produtores e para uma melhor distribuição dessa renda (FURLAN, 2014).

Com base no que foi citado, e, tendo em vista a relevância social e econômica representada pelas cooperativas, além das exigências impostas pelo atual cenário de mercado, tanto nacional quanto internacional, é necessário modernizar e adaptar a gestão das cooperativas, fazendo com que a organização esteja apta a compreender os cenários econômicos e consiga se ajustar a eles (FURLAN, 2014).

\section{Metodologia}

Para a realização da pesquisa descritiva, de natureza exploratória, a amostra contou com 15 profissionais que têm ensino superior completo e que atuam no departamento de gestão de pessoas (RH) de duas cooperativas agroindustriais, uma cooperativa singular, e uma cooperativa central, as quais foram escolhidas por estarem em processo de implantação do modelo de gestão por competências. Ambas têm em comum o trabalho com a avicultura, para abate e processamento de carne de frango. No entanto, a primeira apresenta comércio mais diversificado, contando também com a agricultura, suinocultura, piscicultura e bovinocultura de leite. Ambas possuem relevância econômica e social nas regiões onde estão localizadas, gerando emprego para grande número de pessoas (cerca de 2.000 e $\mathbf{9 . 0 0 0}$ colaboradores), além de utilizarem serviços terceirizados, atuando tanto no comércio interno quanto externo.

Para tanto, o delineamento da amostra ocorreu por meio do método não probabilístico, pelo critério de intencionalidade, no qual os indivíduos são selecionados com base em características tidas como relevantes aos objetivos da pesquisa (KAUARK, MANHÃES e MEDEIROS, 2010).

O instrumento de coleta de dados consistiu em um questionário com duas questões fechadas, uma delas com duas opções de resposta (sim ou não), a qual indagou se o indivíduo possui 
conhecimento sobre o conceito de competência. A outra apresentou dezesseis competências e solicitou que o participante assinalasse as cinco que considera mais importantes para atuação em departamentos de gestão de pessoas. Além destas, o questionário contou com a seguinte questão aberta: "Qual o seu entendimento sobre o conceito de competência?", incluindo também questões pessoais e profissionais, permitindo respostas subjetivas dos participantes. O objetivo foi investigar o entendimento dos profissionais de gestão de pessoas sobre o termo "competência", bem como compreender quais competências eles consideram essenciais para a atuação nessa área. Este instrumento foi criado a partir do levantamento bibliográfico de artigos sobre competências individuais, bem como sobre as competências organizacionais que tornaram-se conhecidas através de material disponibilizado pelas duas cooperativas.

Assim que foi aprovado pela Plataforma Brasil, deu-se início à coleta de dados. Na sequência, as pesquisadoras entraram em contato com as cooperativas pré-selecionadas e foram definidos data e horário para que visitassem as respectivas organizações, de modo a aplicar o questionário na amostra que foi selecionada intencionalmente com base nos critérios estabelecidos. A aplicação aconteceu em uma terça-feira, durante à tarde. Cada um dos participantes recebeu dois Termos de Consentimento Livre e Esclarecido - TCLE, os quais apresentavam informações importantes sobre o protocolo da pesquisa, sendo fonte de consentimento sobre a sua participação. Posteriormente, o questionário foi entregue à cada um dos participantes para preenchimento, sendo que eles levaram em média 15 minutos para responderam as questões. Ressalta-se que todos os participantes preencheram o questionário completo. Coletados todos os dados, realizou-se a análise quantitativa e qualitativa.

A análise dos dados ocorreu a partir da tabulação por meio do programa Excel, visto que este fornece ferramentas para organizá-los, permitindo visualizar de maneira rápida e fácil as respostas dos participantes. Os elementos coletados nas questões fechadas e uma aberta puderam ser mais facilmente analisados e interpretados. Para tal, foi realizada uma análise de conteúdo, que, segundo Kauark, Manhães e Medeiros (2010), caracteriza-se pelo levantamento e pela sistematização de dados por meio de fichamentos. Assim, as respostas individuais foram transcritas, buscando definições ou palavras semelhantes e divergentes entre as respostas para que fossem categorizadas. Posteriormente, os dados foram interpretados com base na bibliografia levantada e nas competências organizacionais das cooperativas pesquisadas.

\section{Resultados}

O questionário foi respondido por oito mulheres e sete homens, cuja média de idade é de 32 anos. Sete dos participantes são graduados em Administração, representando 46,7\% da amostra pesquisada, e os demais participantes se dividem em 13,3\% com formação em Ciências Contábeis, 13,3\%, em Psicologia, 13,3\% são tecnólogos em recursos humanos, 6,7\%, em Ciências Econômicas, e $6,7 \%$, em História. Quanto ao cargo ocupado atualmente, observou-se que os respondentes, em sua maioria, exercem a função de assistente de gestão de pessoas (33,3\%). Ainda, $60 \%$ dos participantes responderam que nunca haviam atuado em departamentos de gestão de pessoas em outras empresas, e 40\% já trabalharam neste setor, em outra organização. Em relação ao tempo de empresa, a média é de seis anos e três meses, já quanto ao tempo em que exerce o cargo atual, a média é de dois anos.

Sobre a primeira questão, na qual os participantes foram indagados se conheciam ou não o conceito de "competência", todos responderam que sim. Posteriormente, foi solicitado que os profissionais descrevessem seu entendimento sobre competência. Os resultados da análise de conteúdo são apresentados a seguir. 
142 | Um olhar sobre as competências requeridas aos profissionais...

Tabela 1 - Definições de competências apresentadas pelos participantes e número de vezes em que foram citadas.

\begin{tabular}{|c|c|c|}
\hline CATEGORIAS & $\begin{array}{l}\text { DEFINIÇÃO DE COMPETÊNCIA SEGUNDO OS } \\
\text { PROFISSIONAIS PESQUISADOS }\end{array}$ & $\begin{array}{r}\text { № DE } \\
\text { CITAÇÕES }\end{array}$ \\
\hline \multirow[t]{4}{*}{ "CHA" } & Conjunto de conhecimentos, habilidades e atitudes & 2 \\
\hline & Conjunto de conhecimentos e habilidades & 2 \\
\hline & Conhecimentos & 1 \\
\hline & Habilidades & 4 \\
\hline \multirow[t]{3}{*}{ Aprendizado } & Aptidões desenvolvidas & 1 \\
\hline & Adquirido ao longo do tempo & 2 \\
\hline & $\begin{array}{l}\begin{array}{l}\text { Aprendizados } \\
\text { necessárias }\end{array} \\
\text { para desenvolver atividades }\end{array}$ & 1 \\
\hline \multirow[t]{3}{*}{ Prática/Execução } & Colocar em prática de forma assertiva & 1 \\
\hline & $\begin{array}{l}\text { Execução eficiente e eficaz de determinadas } \\
\text { atividades }\end{array}$ & 1 \\
\hline & Executar com qualidade & 1 \\
\hline \multirow[t]{2}{*}{ Entrega } & O que ofereço para um cargo/empresa & 1 \\
\hline & Maneira de cada pessoa para desenvolver atividades & 1 \\
\hline \multirow[t]{8}{*}{ Outras } & Capacidade para lidar com situações diferentes & 2 \\
\hline & Aceitar novos desafios & 1 \\
\hline & Competências mapeiam perfis & 1 \\
\hline & Recurso "nas mãos" de bons gestores & 1 \\
\hline & Características pessoais & 1 \\
\hline & Trabalhar em equipe & 1 \\
\hline & Ter foco & 1 \\
\hline & Confiança & 1 \\
\hline
\end{tabular}

Fonte: Tabela elaborada pelas autoras (2018).

A partir das respostas dos participantes, as definições em categorias diferentes foram agrupadas. Uma delas apresentou como destaque o "CHA", ou seja, grande parte dos participantes definiu competência utilizando as palavras "conhecimentos", "habilidades" e "atitudes". No entanto, verificou-se que as interpretações dos participantes divergiram entre o conjunto de conhecimentos, habilidades e atitudes, conjunto de conhecimentos e habilidades, apenas conhecimentos e apenas habilidades, sendo esta última definição a mais citada. Somente dois participantes (com formação superior em Psicologia e Ciências Contábeis) entenderam "competência” assim como é apresentada por Rabaglio (2015): como um conjunto dos três elementos. Pôde-se perceber uma tendência de grande parte dos indivíduos participantes a entender o conceito de "competência" de forma fragmentada ou incompleta.

Outra categoria refere-se ao aprendizado e envolve definições como aptidões desenvolvidas, adquirido ao longo do tempo e aprendizado para desenvolver atividades necessárias. Freitas e Brandão (2005), evidenciam que é por meio da aprendizagem que os indivíduos conquistam as competências, sendo por meio delas que a aprendizagem, por sua vez, manifesta-se. Barbieri (2012) a aprendizagem é um processo por meio do qual as pessoas adquirem novo conhecimento e insights, que mudam seus comportamentos e ações. O desenvolvimento da aprendizagem tem representado uma necessidade aos indivíduos e às organizações, já que se encontram diante de novos desafios e de grande competitividade, buscando destaque e manutenção no mercado.

Dutra (2017) cita que, ao contratar uma pessoa, além dos conhecimentos e experiências, deve-se considerar sua atuação, sua entrega ao trabalho e realizações. As respostas na primeira categoria, respectivamente, concentraram-se em colocar em prática de forma assertiva, executar de forma eficiente e eficaz determinadas atividades e executar com qualidade. Já na segunda, estão concentrados o que o profissional oferece para um cargo/empresa e a maneira de cada pessoa desenvolver as atividades. Uma observação relevante é que as definições de ambas as categorias foram citadas apenas uma vez. 
141 | Um olhar sobre as competências requeridas aos profissionais...

Com base nos resultados, também foi possível verificar diferentes respostas que não se agrupam às categorias definidas. Esta observação nos permitiu entender que a definição de competência ainda não está consolidada entre os profissionais que atuam no departamento de gestão de pessoas em cooperativas agroindustriais e que apenas dois deles trazem o conceito completo do "CHA", descrito por muitos teóricos como o tripé da competência, sendo cada vez mais utilizado pelas empresas. Isso se dá, conforme documento do Serviço Nacional de Aprendizagem Comercial - SENAC (2015), pois o conceito de competência é utilizado por diferentes áreas do conhecimento, como psicologia, administração, pedagogia, sociologia, economia e ergonomia. Assim, não sendo um tema específico de nenhuma dessas áreas, o significado desta palavra e seu uso podem adquirir diferentes sentidos.

Sabe-se que o conceito de competência não é recente, na verdade, refere-se a uma ideia antiga, porém (re)conceituada e revalorizada devido às transformações que vêm acontecendo nas organizações e no mercado de trabalho (FLEURY e FLEURY, 2013). Apesar de existirem pontos em comum nas diferentes definições do conceito de competência apresentadas pelos autores estudados, é importante ressaltar que não há ainda um consenso no meio acadêmico sobre sua definição, o que pode explicar a adoção da expressão, pelos participantes da pesquisa, com enfoques em diferentes aspectos ligados à "competência".

O questionário também objetivou identificar quais as principais competências requeridas aos profissionais que atuam no departamento de gestão de pessoas em cooperativas, com base na perspectiva dos próprios participantes da pesquisa. Os dados desta questão são analisados na sequência, os quais revelam as cinco competências principais citadas.

Tabela 2 - Cinco principais competências assinaladas pelos participantes.

\begin{tabular}{|c|c|c|c|}
\hline & COMPETÊNCIAS & № & $\%$ \\
\hline & Capacidade de trabalhar em equipes & 9 & $12 \%$ \\
\hline \multicolumn{4}{|l|}{$1^{\mathrm{o}}$} \\
\hline & Capacidade de lidar com situações novas e inusitadas & 8 & $10,7 \%$ \\
\hline \multicolumn{4}{|l|}{$2^{-0}$} \\
\hline & Capacidade de comunicação & 8 & $10,7 \%$ \\
\hline \multicolumn{4}{|l|}{$3^{\mathbf{o}}$} \\
\hline & Capacidade de relacionamento interpessoal & 7 & $9,3 \%$ \\
\hline \multicolumn{4}{|l|}{$4^{-0}$} \\
\hline $5^{-\mathrm{o}}$ & $\begin{array}{l}\text { Ter foco no cliente, estabelecendo relação de confiança e } \\
\text { assegurando uma relação de longo prazo }\end{array}$ & 6 & $8 \%$ \\
\hline
\end{tabular}

Fonte: Tabela elaborada pelas autoras (2018).

Neste trabalho, entendeu-se "competências requeridas" como aquelas que são necessárias para a realização das atividades profissionais, e "competências organizacionais" como o conjunto de recursos que propiciam vantagem competitiva a uma organização, frente aos desafios do mercado atual. Considerando que a pesquisa teve por objetivo conhecer as competências requeridas aos profissionais de gestão de pessoas para a atuação em cooperativas agroindustriais, julgou-se relevante relacionar as respostas dos participantes sobre as cinco principais competências requeridas para o seu exercício profissional com as competências organizacionais apontadas pelas duas cooperativas. A saber: priorizar a qualidade dos processos e buscar melhorias contínuas para o aperfeiçoamento deles, empreendedorismo, ter foco em resultados, ter foco no cliente, liderança, capacidade de comunicação, capacidade de relacionamento interpessoal, e iniciativa de ação e decisão.

Dessa forma, de acordo com os resultados, entre as cinco principais competências requeridas para o exercício profissional apontadas pelos participantes pesquisados, duas delas, capacidade de 
trabalhar em equipes e capacidade de lidar com situações novas e inusitadas, não são competências organizacionais das cooperativas pesquisadas. No entanto, capacidade de comunicação, capacidade de relacionamento interpessoal e foco no cliente são competências presentes no quadro de competências organizacionais dessas empresas.

Sendo que, de cinco competências, três são competências listadas pelas organizações pesquisadas, entendeu-se que sim, há relação entre aquelas que foram apontadas pelos participantes e as indicadas pelas cooperativas.

Considerando um estudo realizado em uma cooperativa de crédito de uma cidade do estado de Minas Gerais, os autores afirmaram ser possível perceber diferenças entre o ambiente cooperativo das demais instituições financeiras. E que isso se dá principalmente "nas práticas de trabalho, devido a participação direta dos associados no relacionamento com os colaboradores da Cooperativa" (LADEIRA, VIEIRA e CAMPOS, 2011).

\section{Considerações finais}

A partir da pesquisa bibliográfica e resultados obtidos, observou-se que, apesar de todos os participantes terem respondido que possuem entendimento sobre o conceito de competência, as definições, em sua maioria, ilustram um entendimento incompleto do termo. Entretanto, considerando a inexistência de um consenso sobre o mesmo, pode-se entender a diversidade de enfoques apresentados nas respostas dos participantes.

Referindo-se ao problema da pesquisa, "quais são as competências requeridas para a atuação de profissionais de gestão de pessoas em cooperativas agroindustriais do Paraná, diante dos desafios que permeiam o cenário organizacional atual?", considera-se que o mesmo foi respondido por meio do instrumento utilizado (questionário), sendo que a tabulação dos dados coletados trouxe como resultado as competências a seguir: capacidade de trabalhar em equipes, capacidade de lidar com situações novas e inusitadas, capacidade de comunicação, capacidade de relacionamento interpessoal, e foco no cliente, estabelecendo relação de confiança e assegurando uma relação de longo prazo. Comparando essas respostas com as competências organizacionais das cooperativas participantes, percebeu-se que houve relação entre elas.

Evidencia-se que, com as mudanças organizacionais que vêm ocorrendo nos últimos anos, o conceito de competência tem se tornado mais amplo. Apesar de comumente adotar-se a sigla CHA (Conhecimentos, Habilidades e Atitudes) para interpretar a competência, observa-se uma tendência nova de defini-la como CHAVE, em que o acréscimo de V representa Valores, e E, Entorno. Sousa (2015), esclarece que não basta apenas ser competente, é essencial que o colaborador se identifique com os valores e com a cultura difundida pela organização. Esta mesma autora ainda menciona sobre o entorno, referindo-se ao ambiente e todas as ferramentas necessárias para que o colaborador desenvolva o trabalho que a organização espera.

Com o desenvolvimento do conceito, entende-se que os desafios organizacionais aumentam, já que há exigências maiores na busca por colaboradores realmente competentes e que estejam atrelados com os valores da organização. Além disso, há ainda a preocupação com o fornecimento de ambiente (entorno) propício para que atuem e os resultados sejam obtidos para ambos os lados, organização e colaborador.

A partir desta pesquisa, as cooperativas poderão identificar mais facilmente quais são as competências necessárias aos profissionais que atuam no departamento de gestão de pessoas, de forma a alinha-las ao perfil esperado nesses sujeitos, o que possibilita seleções mais efetivas, bem como a criação de estratégias que promovam a manutenção e o desenvolvimento dessas competências. No entanto, é importante ressaltar que o presente estudo traz a realidade de apenas duas cooperativas do estado, sendo interessante que mais estudos sejam realizados para enriquecer 
143 | Um olhar sobre as competências requeridas aos profissionais...

as discussões sobre essa temática, podendo confirmar ou contrapor os resultados obtidos, bem como, contribuir para um maior consenso sobre o conceito de competência, de modo que possa ser utilizado com mais eficiência dentro das organizações.

Sugere-se ainda a realização de estudos comparativos adicionais entre as competências de profissionais de Gestão de Pessoas (RH) de sociedades cooperativas e sociedades mercantis de modo a compreender se existem diferenças e particularidades entre ambas, objetivando contribuir cada vez mais para o desenvolvimento de conhecimentos úteis à sociedade, ao público acadêmico e especialmente aos profissionais que atuam na área e às cooperativas.

\section{Referências}

ACI - Aliança Cooperativa Internacional. Disponível em: https://www.ica.coop/. Acesso em: 29 de maio de 2018.

ALENCA, E. et al. Complexos agroindustriais, cooperativas gestão. (2001). Disponível em: ageconsearch.umn.edu/bitstream/43377/2/revista_v3_n2_jul-dez_2001_4.pdf. Acesso em: 26 de maio de 2018.

ÁVILA, L. V.; STECCA, J. P. Gestão de pessoas. Santa Maria: Universidade Federal de Santa Maria, Colégio Politécnico; Rede e-Tec Brasil, 2015. Disponível em: estudioo1.proj.ufsm.br/cadernos_cooperativismo/terceira_etapa/arte_gestao_pessoas.pdf. Acesso em: 07 de maio de 2018.

BARBIERI, U. F. Gestão de pessoas nas organizações: conceitos básicos e aplicações. São Paulo: Atlas, 2016.

BITENCOURT, C. (et al.) Gestão contemporânea de pessoas: novas práticas, conceitos tradicionais. 2 ed. Porto Alegre: Bookman, 2010.

CAMARGO, M. D. Plano de desenvolvimento organizacional a partir do mapeamento de competências individuais. Universidade Federal do Paraná. Curitiba, 2013. Disponível em acervodigital.ufpr.br/bitstream/handle/1884/30383/R\%20\%20D\%20\%2oMERICLER\%2oDONEDA\%2 oCAMARGO.pdf?sequence=1\&isAllowed $=$. . Acesso em: o4 de maio de 2018.

CANÇADO, A. C., SOUZA, M. F. A., PEREIRA, J. R. Os princípios cooperativistas e a identidade do movimento cooperativista em xeque (2014). Disponível em: periodicos.ufsm.br/index.php/rgc/article/viewFile/16279/pdf. Acesso em: o6 de maio de 2018.

CARDOSO, U. C.; CARNEIRO, V. L. N.; ROGRIGUES, E. R. Q. Cooperativa. Brasília: Sebrae, 2014. Disponível

em: www.bibliotecas.sebrae.com.br/chronus/ARQUIVOS_CHRONUS/bds/bds.nsf/65for 76 ca $446 f_{4} 66864$ 3bc4e4c5d6add/\$File/5193.pdf. Acesso em: 07 de maio de 2018.

CARVALHO, A. D.; SILVA, B. A. R. A gestão de pessoas e o relacionamento interpessoal no cooperativismo. Revista de Carreiras e Pessoas (ReCaPe). Vol. 7. № 3, pg. 139 - 150. Dez. 2017. Disponível em: revistas.pucsp.br/index.php/ReCaPe/article/view/34942/24299. Acesso em: o8 de maio. 2018.

DUTRA, J. S. Competências: conceitos, instrumentos e experiências. 2. ed. São Paulo: Atlas, 2017.

DUTRA, G. A.; DUTRA, J. S.; DUTRA, T. A. Gestão de pessoas: Realidade atual e desafios futuros. São Paulo: Atlas, 2017. 
FERNANDES, B. H. R. Gestão estratégica de pessoas com foco em competências. 1. Ed. Rio de Janeiro: Elsevier, 2013.

FERREIRA, M. A. M.; BRAGA, M. J. Diversificação e competitividade nas cooperativas agropecuárias. Disponível em: http://www.scielo.br/scielo.php?script=sci_arttext\&pid=S141565552004000400003. Acesso em: o6 de maio de 2018.

FLEURY, A.; FLEURY, M. T. L. Construindo o Conceito de Competência. RAC, Edição Especial, 2001: 183-196. Disponível em www.scielo.br/scielo.php?script=sci_arttext\&pid=S141565552001000500010. Acesso em: o1 de maio. 2018.

FLEURY, A.; FLEURY, M. T. L.. Estratégias empresariais e formação de competências: Um quebra-cabeça caleidoscópico da indústria brasileira. 3. ed. São Paulo: Editora Atlas S.A., 2013.

FRANÇA, A. C. L. Práticas de recursos humanos - PRH: Conceitos, ferramentas e procedimentos. - 1.ed. - São Paulo: Atlas, 2013.

FURLAN, M. Planejamento estratégico como ferramenta de gestão nas cooperativas agroindustriais do Paraná. Revista Capital Científico - Eletrônica (RCCe). Vol. 12 n.4. Outubro/Dezembro, 2014. Disponível em: revistas.unicentro.br/index.php/capitalcientifico/article/view/3166/2409. Acesso em: 26 de maio. 2018.

KAUARK, F.; MANHÃES, F. C.; MEDEIROS, C. H. Metodologia da pesquisa: guia prático. Itabuna: Via Litterarum, 2010.

KOSLOVSKI, J. P. Cooperativismo paranaense: experiências, resultados e propostas. Curitiba: Ocepar, 2018.

LADEIRA, M. A.; VIEIRA, N. S.; CAMPOS, D. C. S. As competências nas cooperativas de crédito: O caso do SICOOB Carlos Chagas - MG. XIV SemeAd: 2011. Disponível em: sistema.semead.com.br/14semead/resultado/trabalhosPDF/689.pdf. Acesso em: 12 de agosto de 2019. LE BOTERF, G. Avaliar a competência de um profissional: três dimensões a explorar. Reflexão RH, 2006. Disponível em: http://www.guyleboterfconseil.com/Article\%2oevaluation\%2oversion\%2odirecte\%2oPessoal.pdf. Acesso em: 16 de maio.2018.

LOPES, C. Entrevistas e seleção por competências. São Paulo: Editora Integração, 2014.

OCB - Organização das Cooperativas Brasileiras. Disponível em http://www.ocb.org.br/ocb. Acesso em: or de maio de 2018.

RABAGLIO, M. O. Gestão por competências: ferramentas para atração e captação de talentos humanos. 3. ed. Rio de Janeiro: Qualitymark, 2015.

REISDORFER, V. K. Introdução ao cooperativismo (2014). Disponível em: estudioo1.proj.ufsm.br/cadernos_cooperativismo/primeira_etapa/arte_introduc_cooperativismo.pdf. Acesso em: o6 de maio. 2018.

SANT'ANNA, A. S. et al. Competências individuais e modernidade organizacional: um estudo comparativo entre profissionais de organizações mineiras e baianas (2016). Disponível em: www.scielo.br/pdf/gp/v23n2/0104-530X-gp-0104-530X1191-15.pdf. Acesso em: 28 de maio. 2018. 
145 | Um olhar sobre as competências requeridas aos profissionais...

SANTIAGO, A. C. Q. As competências das pessoas: potencializando seus talentos. São Paulo: DVS, 2008.

SISTEMA OCEPAR. Disponível em: www.paranacooperativo.coop.br/ppc/images/Comunicacao/2019/download/cenarios_cooperativism o/ramo_agropecuario_fechamento_2018_publico.pdf. Acesso em: 21 de jul. 2019.

TACHIZAWA, T.; FERREIRA, V. C. P.; FORTUNA, A. A. M. F. Gestão com pessoas: uma abordagem aplicada às estratégias de negócio. 5. Ed. - Rio de Janeiro: Editora FGV, 2006.

WAACK, R. S.; MACHADO FILHO, C. P. Administração estratégica em cooperativas agroindustriais (1999). Disponível em: www.researchgate.net/profile/Claudio_Machado_Filho/publication/228711853_Administracao_estrat egica_em_cooperativas_agroindustriais/links/54ade7a1ocf2213c5fe41c27/Administracao-estrategicaem-cooperativas-agroindustriais.pdf. Acesso em: 06 de maio. 2018. 